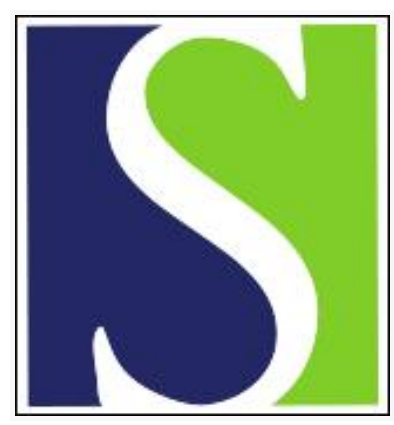

Scand J Work Environ Health 1979;5(3):280-285

https://doi.org/10.5271/sjweh.3102

Issue date: Sep 1979

Temperature changes in contact lenses in connection with radiation from infrared heaters

by Lövsund P, Nilsson SEG, Öberg PÅ

Affiliation: Department of Ophthalmology, University Hospital, University of Link6ping, S-581 85 Linköping, Sweden.

Refers to the following texts of the Journal: 1979;5(3):271-279

1979;5(3):262-270

The following article refers to this text: 1979;5(3):271-279

Key terms: contact lense; corneal damage; heater; infrared heater; occupational safety; radiation; radiation hazard; soft contact lense; temperature; temperature change; worker safety

This article in PubMed: www.ncbi.nlm.nih.gov/pubmed/20120576

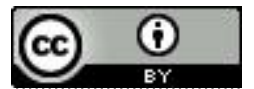




\title{
Temperature changes in contact lenses in connection with radiation from infrared heaters
}

\author{
by PER LÖVSUND, M.Sc.E.E., ${ }^{1}$ SVEN ERIK G. NILSSON, M.D., Ph.D.,² \\ and P. ÅKE ÖBERG, Ph.D. ${ }^{1}$
}

\begin{abstract}
LOVSUND, P., NILSSON, S. E. G. and OBERG, P. A. Temperature changes in contact lenses in connection with radiation from infrared heaters. Scand. $j$. work environ. \& health 5 (1979) 280-285. A number of reports have appeared over the past few years with warnings about the wearing of contact lenses in certain trades involving exposure to arc flash. In view of these reports and in light of knowledge on the marked absorption by contact lenses, within the infrared (IR) region, temperature changes were measured in soft contact lenses under radiation from IR heaters used, for example, in the motor industry for drying paint. The lenses were tested while free-hanging and when applied to rabbit eyes. Great increases in temperature were noted with one of the heaters at a distance corresponding to "safe." During $10 \mathrm{~min}$ of exposure the temperature of a free-hanging lens rose from 21 to $59^{\circ} \mathrm{C}$, whereas the temperature in the surrounding air increased only from 26 to $30^{\circ} \mathrm{C}$. The final temperature of the lens was thus $29^{\circ} \mathrm{C}$ higher than that of the air. In lenses applied to rabbit eyes the temperature rose within only $0.5,1.0$, and 1.5 min from approximately $33^{\circ} \mathrm{C}$ to about 44,49 , and $51^{\circ} \mathrm{C}$, respectively; the air temperature rose from 25 to only $28^{\circ} \mathrm{C}$. In other words, the ultimate lens temperature was $23^{\circ} \mathrm{C}$ higher than the ambient air temperature. In the rabbit experiments most of the lenses dried out completely. There would thus seem to be considerable risk of contact lenses drying and becoming adherent to and damaging the corneal surface among workers exposed to powerful radiation from IR radiators (IR heaters), unless they use efficient eye protectors. IR heaters appear to be associated with greater hazards than arc flashes, since there is no warning from powerful visible light and because they are capable of causing a very rapid increase in temperature.
\end{abstract}

Key words: corneal damage, infrared heaters, radiation hazards, soft contact lenses, temperature changes, worker safety.

It has been asserted on several occasions in the literature that welding arcs and other high-energy arcs may constitute a serious hazard for wearers of contact

1 Department of Biomedical Engineering, University of Linköping, Sweden.

2 Department of Ophthalmology, University of Linköping, Sweden.

Reprint requests to: Prof. S. E. G. Nilsson, Department of Ophthalmology, University Hospital, University of Linköping, S-581 85 Linköping, Sweden. lenses $(1,4,7,9,10,13)$. The case that set off the discussion was that of a shipyard worker with contact lenses who developed corneal lesions after exposure to a powerful flash occurring when a circuit breaker arced during the connection of a welding cable. $\mathrm{He}$ was wearing safety glasses at the time. It has since been alleged that the injury was due to $17-18 \mathrm{~h}$ of continuous wearing of the lenses $(8,10,11$, 12) and that the original report was nothing but an "industrial atrocity story" (12). No experimental investigations on the 
problem have been carried out to our knowledge however, and existing reports offer too flimsy a basis for recommendations to contact lens wearers exposed daily to electric arcs or other radiation. It therefore seems a matter of interest to elucidate the question.

This investigation is a direct continuation of studies on the transmittance and absorption properties of certain contact lens materials (3) and on temperature changes in contact lenses during radiation from certain welding processes (2) that we have carried out. We have shown that marked absorption occurs in the infrared (IR) region (3). The present work was therefore undertaken to investigate the temperature changes that take place in contact lenses on exposure to radiation from two different IR heaters.

IR heaters are used, for example, in the motor industry and at workshops for drying paint on cars. It is suspected that IR radiation may cause damage to the eyes (radiation cataract). The Swedish National Board of Occupational Safety and Health has therefore analyzed work conditions in connection with IR heaters and has also investigated the emission from 10 common heaters (6). The heaters were examined with regard to spectral distribution, radiance at different distances, source area, luminance, and other factors.

\section{MATERIAL AND METHODS}

\section{Temperature recordings}

Copper-constantan (T) thermocouples (High Temperature Instruments Corporation, U.S.A.) were used. The tips were flattened to approximately $80 \mu$. The temperature was read from a five-channel digital indicator (Doric, U.S.A.) with a resolution of $0.1^{\circ} \mathrm{C}$ and with built-in linearization and compensation for the cold junction.

The following control experiment was done to establish whether a false rise in temperature may occur as a result of IR radiation absorption by the naked thermocouple. Two identical thermocouples were mounted at the same level and $0.2 \mathrm{~m}$ apart at a distance of $0.5 \mathrm{~m}$ from one of the IR heaters (Adcoat). A powerful air current was fanned over them from one side. The same air temperature was recorded by both thermocouples. When one of them was screened from the IR radiation no change in temperature was noted in either thermocouple. Thus, no false temperature increase from the absorption of IR radiation by the naked thermocouple was found.

\section{Infrared heaters}

IR radiation was generated by two different heaters, Elektrofem (IF-03, $6 \mathrm{~kW}$ ) and Adcoat $\mathrm{AB}$ (IR 2200, $2.2 \mathrm{~kW}$ ). Their main specifications are summarized in table 1 and fig. 1. The "safe distances" calculated for the heaters are taken from the recommendations of the Swedish National Board of Occupational Safety and Health (6), and they are based on the estimated risk of cataract caused by absorption of near IR radiation by the lens of the eye (5).

Measurement of temperature in freehanging contact lenses

Soft lenses of the HEMA (hydroxyethyl methacrylate) type were used. The thermocouple was placed at the center of the lens with the probe tip inside the lens. The lens was thoroughly wet with physiological saline at the start of each recording. Two makes of lens were used, Weicon $+\mathbf{1 5 . 5 0}$ $\mathrm{D}$ or Soflens $+17.00 \mathrm{D}$, both of which have a water content of $39 \%$ and a lens thickness (in the wet state) of approximately $0.5 \mathrm{~mm}$ at the point where the temperature was recorded. A second thermocouple placed in front of the lens was used to record air temperature. The radiation from the IR heater was directed towards the front of the lens.

Measurement of temperature in contact lenses applied to rabbit eyes

The experiments with rabbits were done so that the true conditions at a place of work could be reproduced as closely as possible. Soft, HEMA-type lenses were used, applied to the eyes of adult, pig- 
Table 1. Specifications of the infrared heaters [from Ruth et al. (6)].

\begin{tabular}{lccccc}
\hline $\begin{array}{l}\text { Infrared } \\
\text { heater }\end{array}$ & $\begin{array}{c}\text { Spectral } \\
\text { region } \\
(\mathrm{nm})\end{array}$ & $\begin{array}{c}\text { Approx. } \\
\text { radiation max. } \\
(\mathrm{nm})\end{array}$ & $\begin{array}{c}\text { Power } \\
(\mathrm{kW})\end{array}$ & $\begin{array}{c}\text { Luminance } \\
\left(\mathrm{cd} / \mathrm{m}^{2}\right)\end{array}$ & $\begin{array}{c}\text { Safe } \\
\text { distance } \\
(\mathrm{m})\end{array}$ \\
\hline $\begin{array}{l}\text { Elektrofem } \\
\text { IF-03 }\end{array}$ & $1,000->3,200$ & 2,500 & 6.0 & 0 & 0.5 \\
$\begin{array}{l}\text { Adcoat } \mathrm{AB}, \\
\text { IR 2200 }\end{array}$ & $750->3,200$ & 3,300 & 2.2 & 40 & 1.0 \\
\hline
\end{tabular}

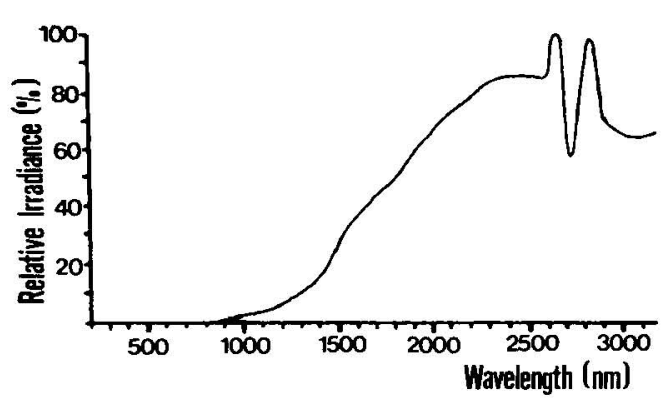

ELEKTROFEM 6WW

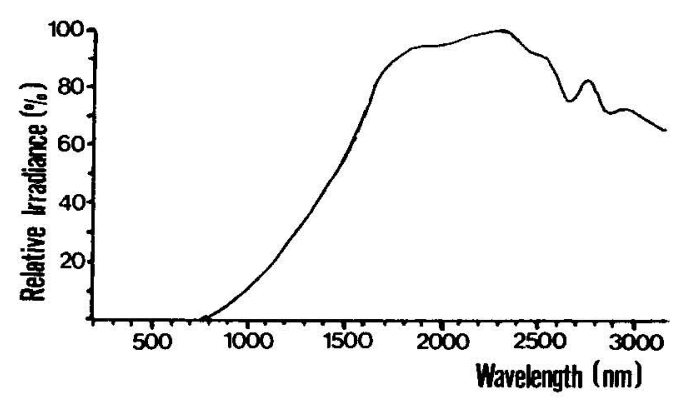

ADCOAT $2.2 \mathrm{~kW}$

Fig. 1. Spectral distribution curves for the two infrared heaters [from Ruth et al. (6)].

mented rabbits. The animals were awake and unanesthetized.

In these experiments it proved impossible to retain the thermocouple in a single lens, as it became dislocated by the least eye movement. A double lens (one Hydron $-1.75 \mathrm{D}$ and one Soflens $+3.50 \mathrm{D}$ ) was therefore constructed in which the radii of curvature of the inner lens matched exactly those of the cornea and the posterior surface of the outer lens. The lenses were glued together at the extreme periphery, and the thermocouple, flexed to fit, was introduced between the wet lenses, care being taken to exclude air bubbles. The wet combination was $0.6 \mathrm{~mm}$ thick at the measuring point. In these experiments only the Elektrofem heater was used.

Changes in air temperature were recorded with a thermocouple in front of the lens. The animal was arranged so that the optical axis of the eye under investigation was directed towards the IR heater. The lenses were rewet between each experiment.

\section{RESULTS}

Temperature changes in free-hanging contact lenses

Temperature changes in the lenses and the surrounding air during $10 \mathrm{~min}$ of continuous radiation from each of the two IR heaters at a distance of $0.5 \mathrm{~m}$ are shown in table 2. No significant difference was found between the two types of lens, and the results are therefore given as the means of the two. In absolute figures the lens temperature increased in 1,3 , and 10 min from $21^{\circ} \mathrm{C}$ to 42,50 , and $59^{\circ} \mathrm{C}$, respectively, with the Elektrofem heater. With the Adcoat the lens temperature rose from 20 to $45^{\circ} \mathrm{C}$ in $10 \mathrm{~min}$. The air temperature rose from 26 to $30^{\circ} \mathrm{C}$ and from 25 to $28^{\circ} \mathrm{C}$ for the two heaters, respective$1 y$; in other words the final temperatures in the lenses were 29 and $17^{\circ} \mathrm{C}$ higher than in the surrounding air. With Elektrofem the distance tallied with the "safe distance." For Adcoat the "safe distance" is 
$1 \mathrm{~m}$, however, and with radiation at this distance the lens temperature did not increase more than that of the surrounding air.

Temperature changes in contact lenses applied to rabbit eyes

It was found that in the conscious animal the unanesthetized eye, equipped with a double lens, was often shut or almost shut when exposed to the IR heater. When the eye was completely shut, the increase in temperature was halted or reversed. The results are therefore divided into recordings made with the eye open and with an approximately $3-\mathrm{mm}$ palpebral fissure. The distance was $0.5 \mathrm{~m}$, which corresponds to the "safe distance" for the Elektrofem heater. The results are given in table 3 and fig. 2. Exposures of $0.5,1.0$ and 1.5 min with the eye fully open caused the lens temperature to increase from about $33^{\circ} \mathrm{C}$ to approximately 44,49 , and $51^{\circ} \mathrm{C}$, respectively. Because the air temperature rose only from 25 to $28^{\circ} \mathrm{C}$, the increases in the lenses were 16,21 , and $23^{\circ} \mathrm{C}$ greater than in the surrounding air. With an approximately 3-mm palpebral fissure and an exposure time of $1.5 \mathrm{~min}$ the lens temperature increased to only $44^{\circ} \mathrm{C}$ (average).

In all the experiments in which the eye was kept open, and also in several in which the palpebral fissure was slightly smaller, the lenses dried completely and, as a rule, also became deformed and fell out of the eye. In a few cases the lenses became adherent to the corneal surface.

In one experiment the temperature of the naked corneal surface was measured during radiation from the Elektrofem heater at a distance of $0.5 \mathrm{~m}$. The temperature of the corneal surface also rose, and the increase was practically identical to that recorded in the contact lenses.

\section{DISCUSSION}

The two IR heaters tested emit radiation within roughly the same region of the spectrum. The power is nearly three times greater in Elektrofem $(6 \mathrm{~kW})$ than in Adcoat $(2.2 \mathrm{~kW})$, however. Of the heaters tested by the Swedish National Board of Occupational Safety and Health, Elektrofem had the greatest power, whereas Adcoat was among those with the lowest power. Because both generate very little visible light, there is only a limited warning of the radiation, and prolonged exposure may occur. A worker with contact lenses therefore runs the risk that the lenses become overheated, dry out, and become adherent to the corneal surface. The cornea itself and its tear film also show marked absorption in the IR region and consequently also an increase in temperature. Without contact lenses, however, the thin tear film is probably maintained by blinking. On the other hand, it seems

Table 2. Increase in temperature $\left({ }^{\circ} \mathrm{C}\right)$ in wet, free-hanging contact lenses after $10 \mathrm{~min}$ of radiation: A comparison of two infrared heaters.

\begin{tabular}{lcc}
\hline & \multicolumn{2}{c}{ Infrared heater } \\
\cline { 2 - 3 } & Elektrofem $(\mathrm{N}=2)$ & Adcoat $(\mathrm{N}=3)$ \\
\hline Lens temperature & 21 & 20 \\
$\quad$ Initial & 59 & 45 \\
$\quad$ Final & 38 & 25 \\
$\quad$ Increase & 26 & 25 \\
Air temperature & 30 & 3 \\
$\quad$ Initial & 4 & $\mathbf{3}$ \\
$\quad$ Final & & +17 \\
$\quad$ Increase & 29 & \\
Difference between final & & \\
Iens and air temperatures & & \\
\hline
\end{tabular}


Table 3. Increase in temperature $\left({ }^{\circ} \mathrm{C}\right)$ in contact lenses applied to rabbit eyes.

\begin{tabular}{|c|c|c|c|}
\hline & \multicolumn{2}{|c|}{ Eye fully open throughout experiment } & \multirow{2}{*}{$\begin{array}{l}\text { Palpebral fissure } \\
\text { about } 3 \mathrm{~mm} \text { wide, } \\
\text { experimental time } 1.5 \mathrm{~min} \\
(\mathrm{~N}=5)\end{array}$} \\
\hline & $\begin{array}{c}\text { Experimental } \\
\text { time } 1 \text { min } \\
(\mathrm{N}=3)\end{array}$ & $\begin{array}{l}\text { Experimental } \\
\text { time } 1.5 \mathrm{~min} \\
\quad(\mathrm{~N}=1)\end{array}$ & \\
\hline \multicolumn{4}{|l|}{ Lens temperature } \\
\hline Initial & 33 & 32 & 33 \\
\hline Final & 49 & 51 & 44 \\
\hline Increase & 16 & 19 & 11 \\
\hline \multicolumn{4}{|l|}{ Air temperature } \\
\hline Initial & 25 & 25 & 26 \\
\hline Final & 28 & 28 & 28 \\
\hline Increase & 3 & 3 & 2 \\
\hline $\begin{array}{l}\text { Difference between final } \\
\text { lens and air temperatures }\end{array}$ & +21 & +23 & +16 \\
\hline
\end{tabular}

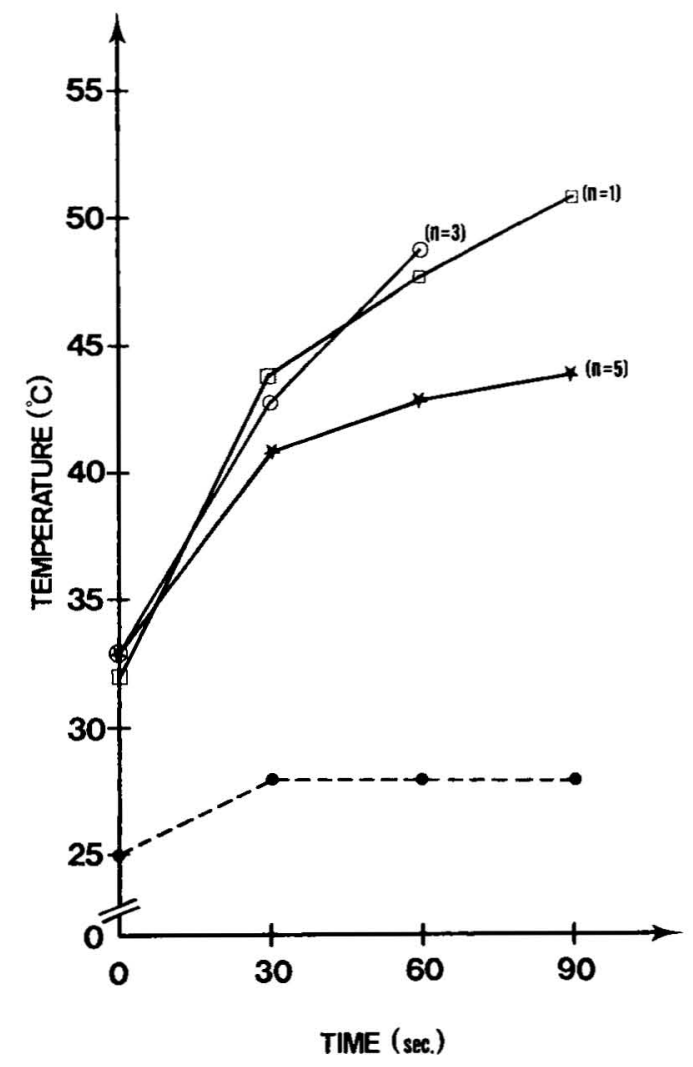

Fig. 2. Increase in temperature in contact lenses applied to rabbit eyes. $10-\mathrm{O}-\mathrm{O}$ and $\square-\square=$ open eyes, $\downarrow-\star \backslash=$ palpebral fissure about $3 \mathrm{~mm}$ wide, $\bullet--\bullet=$ surrounding air temperature) that water-containing contact lenses carry a considerable risk of drying out, and therefore they may become adherent to the corneal surface and cause epithelial lesions. Thus the hazard is not primarily due to the rise in temperature but to the adherence of the contact lens.

No epithelial lesions caused by adherent lenses were found in the rabbit experiments. The rabbit cornea is much more resistant to mechanical trauma than the human counterpart, however. Also, contact lenses are fitted with much greater precision in practice in man than they were in these animal experiments. Furthermore the weight of the thermocouple constituted a force tending to lift the lens from the eye. It may therefore be assumed that the better fit of and the lack of thermocouple force on the human lens will contribute to a more complete adhesion of the lens. Workers should therefore be advised against wearing contact lenses while operating long-wave IR radiators unless they also wear safety glasses that absorb the IR radiation.

Some other IR heaters in use produce radiation of considerably longer wavelengths than the two tested in this study. The hazards with these are undoubtedly even greater, as the emission lies within a region that is absorbed to almost $100 \%$ by contact lenses (3). 


\section{ACKNOWLEDGMENTS}

This investigation was supported by the Swedish Work Environment Fund, project no. $76 / 174$.

We wish to thank Mr. H. Lindh for fitting the contact lenses and Ms. M. Oldbäck, who assisted in the animal experiments.

\section{REFERENCES}

1. FOX, S. L. Industrial and occupational ophthalmology. Charles C. Thomas, Springfield, IL 1973. $203 \mathrm{p}$.

2. LOVSUND, P., NILSSON, S. E. G., LINDH, H. and ÖBERG, P. $\AA$. Temperature changes in contact lenses in connection with radiation from welding arcs. Scand. $j$. work environ. \& health 5 (1979) 271-279.

3. NILSSON, S. E. G., LÖVSUND, P., ÖBERG, P. A. and FLORDAHL, L.-E. The transmittance and absorption properties of con- tact lenses. Scand. j. work environ. \& health 5 (1979) 262-270.

4. NOVAK, J. F. and SAUL, R. W. Contact lenses in industry. J. occup. med. 13 (1971) $175-178$.

5. RUTH, W. A method to evaluate occupational hazards from infrared radiation. Project report submitted in part fulfillment of the requirements for the postgraduate course in ergonomics at the Loughborough University of Technology 1975. $156 \mathrm{p}$.

6. RUTH, W., LEVIN, M. and KNAVE, B. Arbetshygienisk bedömning av infrarödstrålare för torkning av billack. (Undersökningsrapport AMMF 104/76). Arbetarskyddsstyrelsen, Stockholm 1976. $69 \mathrm{p}$.

7. Contact lens hazard. Qual. eng. 38 (1974) 95

8. $\longrightarrow$. Contact lens hazard. Qual. eng. 38 (1974) 150.

9. Contact lenses and arc welders. Br. med. j. 4 (1974) 586.

10. C Contact lenses and electrical arcs. Weld. ins. res. bul. 15 (1974) 43-44.

11. Flash and contact lenses. Occup. saf. health 5 (1975) 11.

12. - An industrial atrocity story. Occup. saf. health 7 (1977) 85.

13. - Position statement - Contact lenses in industry. Ind. med. 41 (1972) 38-39.

Received for publication: 6 November 1979 